\title{
PR PRESENTACIÓN
}

El 29 de junio de 2013 murió Darío Macor, quien fuera desde su fundación, en 1991, hasta esa fecha, director de la revista Estudios Sociales. Quienes formamos parte de la revista creímos que una de las mejores formas de homenajear a Darío era hacerlo desde este espacio que fue para él uno de sus proyectos colectivos más preciados.

Pensamos para ello este número especial que contiene diferentes secciones: la primera que trata de aproximarnos, a partir de una serie de notas breves, al hombre académico, al intelectual, al político.

La sección Artículos reúne un conjunto de textos de historiadores, politólogos y sociólogos cuyo título convocante fue Los problemas de lo político. Prácticas, culturas $y$ sociabilidades, con el cual quisimos de alguna manera sintetizar los diferentes tópicos que formaron parte de las preocupaciones de Darío Macor como historiador.

Un dossier donde se incluyen trabajos sobre «Peronismos provinciales» introducidos por un sugerente texto de César Tcach acerca de la inscripción de trabajos como los aquí presentados en lo que denomina Un cambio en el régimen de preguntas. Los textos incluidos en este dossier formaron parte de una mesa especial del XI Congreso Nacional de Ciencia Politica celebrado en Paraná en agosto de 2013, organizada por Tcach y Macor, pero que no pudo contar con la presencia de éste último.

La sección Comunicaciones recupera una conferencia pronunciada por Juan Carlos Torre en el marco de las VIII Jornadas de Historia Política, organizadas por el Programa Buenos Aires de Historia Política, en la ciudad de Mendoza en septiembre de 2013. En este refinado texto, Torre explora la incidencia de lo que denomina «el factor Perón» en el período de la historia argentina en el que éste tuvo «un protagonismo insoslayable».

Por último en Galería de textos se reúnen escritos de Darío, algunos inéditos y otros no tan difundidos, con la idea de dar cuenta de la diversidad de intereses que balizaron su pasión por comprender y explicar...

Consejo Editorial -

Santa Fe, abril de 2014 